\title{
Suppressive effects of the sodium-glucose cotransporter 2 inhibitor tofogliflozin on colorectal tumorigenesis in diabetic and obese mice
}

\author{
JUNICHI KATO ${ }^{1}$, YOHEI SHIRAKAMI ${ }^{1,2}$, MASAYA OHNISHI ${ }^{1}$, TAKU MIZUTANI ${ }^{1}$, MASAYA KUBOTA ${ }^{1}$, \\ HIROYASU SAKAI $^{1}$, TAKASHI IBUKA ${ }^{1}$, TAKUJI TANAKA ${ }^{3}$ and MASAHITO SHIMIZU ${ }^{1}$ \\ Departments of ${ }^{1}$ Gastroenterology and ${ }^{2}$ Informative Clinical Medicine, Gifu University Graduate School of Medicine, \\ Gifu 501-1194; ${ }^{3}$ Department of Pathological Diagnosis, Gifu Municipal Hospital, Gifu 500-8513, Japan
}

Received May 17, 2019; Accepted September 5, 2019

DOI: $10.3892 /$ or.2019.7357

\begin{abstract}
Sodium-glucose cotransporter 2 inhibitors were developed for the treatment of diabetes mellitus. Although recent studies have indicated that sodium-glucose cotransporter 2 inhibitors have suppressive effects on several types of cancer, their effects against colorectal cancer remain unknown. The purpose of the present study was to investigate the effects of tofogliflozin, a sodium-glucose cotransporter 2 inhibitor, on the development of colorectal cancer in diabetic and obese mice. The direct effects of tofogliflozin on the proliferation of colorectal cancer cells were also evaluated. $\mathrm{C} 57 \mathrm{BL} / \mathrm{KsJ}-d b / d b$ mice were injected with azoxymethane to induce colorectal pre-malignancy and they received drinking water with or without tofogliflozin. At the end of the study, administration of tofogliflozin was revealed to significantly suppress the development of colorectal neoplastic lesions and $\beta$-catenin accumulated crypts. In the tofogliflozin-treated mice, the levels of blood glucose and serum TNF- $\alpha$, as well as mRNA expression of the pro-inflammatory markers in the white adipose tissue, were reduced. Furthermore, macrophage infiltrations in the white adipose tissues were also reduced significantly. The proliferation of the sodium-glucose cotransporter 2-expressing human colorectal cancer cells was not altered by tofogliflozin. These results indicated that tofogliflozin ameliorated chronic inflammation and hyperglycemic condition leading to prevention of colorectal tumorigenesis in a diabetes- and obesity-related colorectal cancer model.
\end{abstract}

\section{Introduction}

Colorectal cancer (CRC) is a serious health concern worldwide although technologies for early detection and early

Correspondence to: Dr Yohei Shirakami, Department of Gastroenterology, Gifu University Graduate School of Medicine, 1-1 Yanagido, Gifu 501-1194, Japan

E-mail: ys2443@gifu-u.ac.jp

Key words: colorectal cancer, SGLT2 inhibitor, diabetes, insulin-like growth factor, $\beta$-catenin accumulated crypts treatment are progressing. Globally, CRC is the third most commonly diagnosed cancer and the fourth leading cause of cancer-related deaths in males, the second and the third, respectively, in females (1). Recent evidence has indicated that obesity and its associated metabolic abnormalities, such as diabetes and dyslipidemia are related to an increased risk of CRC $(2,3)$. Type 2 diabetes mellitus is a major complication of obesity and its prevalence is high and increasing. In addition to cardiovascular and cerebrovascular events, cancer is also a major cause of diabetes- and obesity-related deaths (4-6).

The patients with diabetes have increased risk of many types of cancer, especially cancer of the colon, liver, and pancreas (7). The mechanisms by which diabetes promotes the development and progression of cancer including CRC have been only partially elucidated. These include chronic inflammation, oxidative stress, hyperglycemia, and insulin resistance (8-11), which are thought to be caused by metabolic abnormalities. Previously, it was reported that diet- or drug-induced diabetic and obese mice were significantly susceptible to colon tumorigenesis in carcinogen-induced colon cancer models $(12,13)$. In addition, recent studies have revealed that several types of natural compounds and medicines, including catechins obtained from green tea, curcumin, and pentoxifylline suppressed the development of diabetesand obesity-related colorectal tumorigenesis partially by attenuating chronic inflammation (14-16). These findings indicated that diabetes- and obesity-associated metabolic abnormalities may be important targets for preventing colon cancer development in diabetic and/or obese individuals (10). Several clinical studies have actually demonstrated that certain types of anti-diabetic drugs could reduce the risk of CRC (17,18).

Sodium-glucose cotransporter 2 (SGLT2) inhibitors were developed for the treatment of diabetes by preventing reabsorption of glucose filtered through the glomeruli and increasing its urinary excretion $(19,20)$. This phenomenon reduces blood glucose levels and improves insulin resistance in patients with diabetes as well as in several rodent models of diabetes (21-23). Cancer cells demonstrate uptake of glucose, a major metabolic substrate required for cancer growth via glucose transporters including SGLT. Therefore, the anticancer effects of SGLT inhibitors have gained much attention. Recent publications have indicated that SGLT2 inhibitors prevented carcinogenesis 
and inhibited cancer growth in several types of cancer (24-26), however, little is known on whether the SGLT2 inhibitors have efficacy against CRC.

In the present study, in order to examine the effects of an SGLT2 inhibitor on CRC, it was investigated whether the development of azoxymethane (AOM)-induced colorectal pre-neoplastic lesions in diabetic and obese $d b / d b$ mice was suppressed by a highly selective SGLT2 inhibitor tofogliflozin (27). In addition, the direct effects of tofogliflozin on CRC cell proliferation were also examined.

\section{Materials and methods}

Animals and housing conditions. Twenty-four male $d b / d b$ mice (5 weeks old) were obtained from Japan SLC Inc. They were acclimatized for a week before initiation of the experiment (16). They were carefully handled and humanely maintained at the Gifu University Life Science Research Center in accordance with the Institutional Animal Care Guidelines. The mice were housed in cages and were provided basic diet CE-2 obtained from Oriental Yeast and sterilized tap water ad libitum. The environmental conditions inside the room were as follows: Temperature, $23 \pm 1^{\circ} \mathrm{C}$; humidity, $50 \pm 20 \%$; and 12 -h light/dark cycle.

Chemicals and methods of drug administration. AOM was obtained from Wako Pure Chemical Co. and was intraperitoneally injected once weekly from weeks 1 to 4 after initiation of the experiment. AOM was diluted with ultra-pure water to administer a dose of $15 \mathrm{mg} / \mathrm{kg}$ body weight. Tofogliflozin was kindly provided by Kowa Co., Ltd. Tofogliflozin $(1 \mathrm{mg} / \mathrm{kg}$ body weight and $10 \mathrm{mg} / \mathrm{kg}$ body weight) was dissolved in ultra-pure water. The solution was poured into the bottles and exchanged twice a week.

Procedure of the animal experiment. At five weeks of age, the mice were randomly divided into four experimental groups and treated as follows: No treatment (Group $1, \mathrm{n}=5$ ), AOM alone (Group 2, $\mathrm{n}=9$ ), AOM followed by tofogliflozin $(1 \mathrm{mg} / \mathrm{kg}$ body weight) in drinking water (Group 3, n=5), and tofogliflozin alone (Group 4, n=5). Group 2 and 3 mice were injected with AOM $(15 \mathrm{mg} / \mathrm{kg}$ body weight $)$ intraperitoneally once weekly from weeks 1 to 4 after initiation of the experiment. Mice were not anesthetized prior to AOM injection. At 9 weeks of age, the Group 3 and 4 mice received drinking water containing tofogliflozin. At 24 weeks of age, counting from 14 weeks of tofogliflozin treatment, all the mice were euthanized after $12 \mathrm{~h}$ of fasting. Then, blood samples were collected from the inferior vena cava for clinical chemistry and organs and tissues were removed for histopathological examination. For euthanasia, after inhalation of $\mathrm{CO}_{2}$ the chest cavity was opened, and the heart was exposed and viewed directly to confirm death. The experimental protocol was approved by the Committee of Institutional Animal Experiments of Gifu University (authorization code: 30-7, dated 13 April 2018).

Histopathological examination. The livers, kidneys, white adipose tissues, and colorectal tissues were excised. The colon and rectum were opened longitudinally and fixed on a filter paper in $10 \%$ buffered formalin for more than $24 \mathrm{~h}$. It was divided into a rectal portion (approximately $1 \mathrm{~cm}$ in length on the oral side from the dentate line) and colonic portion. Each segment and the other tissues were paraffin-embedded. From the rectal tissue blocks, two serial sections were subjected to hematoxylin and eosin (H\&E) staining for histopathology and immunohistochemistry for $\beta$-catenin to evaluate the development of $\beta$-catenin accumulated crypts (BCACs) (16). Immunohistochemical analyses for $\beta$-catenin (1:1,000 dilution, BD Transduction Laboratories) was performed using a labeled streptavidin-biotin method (LSAB kit; DAKO; Agilent Technologies, Inc.). Immunohistochemical staining for F4/80 was also performed to examine macrophage infiltration in the adipose tissues, according to a previous study (28) with primary antibody (1:100 dilution; product code ab111101; Abcam). Immunoreactivity was considered as positive when apparent staining was detected in the cytoplasm and/or nuclei $(28,29)$.

Clinical chemistry. Serum was centrifuged (1,600 x g for $15 \mathrm{~min})$ from the whole blood and was used for chemical analyses. Serum glucose, insulin, total cholesterol, free fatty acid (FFA), and triglyceride (TG) levels were determined by a commercial laboratory (SRL, Inc.). Serum TNF- $\alpha$ levels were estimated by mouse TNF- $\alpha$ ELISA kit (AKMTM-011; Shibayagi Co. Ltd.) in accordance with the manufacturer's protocol.

mRNA extraction and $q R T-P C R$ analysis. The mRNA expression in the colonic mucosa of the experimental mice was examined using quantitative real-time reverse transcription-polymerase chain reaction (qRT-PCR) analysis. Total RNA was isolated from the scraped colonic mucosa of all the experimental mice using PureLinkTM RNA Mini Kit (Invitrogen; Thermo Fisher Scientific, Inc.), according to the manufacturer's instructions. The complementary DNA (cDNA) was amplified from $1.5 \mu \mathrm{g}$ of total-RNA of each sample using High Capacity cDNA Reverse Transcription Kit (Applied Biosystems; Thermo Fisher Scientific, Inc.). The primers used for the amplification of C-C motif chemokine-2 $(C C L-2)$, tumor necrosis factor- $\alpha(T N F-\alpha), \mathrm{F} 4 / 80$, insulin-like growth factor-1 (IGF-1), insulin-like growth factor-2 (IGF-2), insulin-like growth factor binding protein-3 (IGFBP-3), and $18 S$ specific genes were previously reported $(30,31)$ or as follows: $I G F-1$ forward, 5'-TCGGCCTCATAGTACCCACT-3' and reverse, 5'-ACGACATGATGTGTATCTTTATTGC-3'; $I G F-2$ forward, 5'-ACCTTCGGCCTTTGTCTGGTA-3' and reverse, 5'-CGAAGGCCAAAGAGATGAGA-3'; and IGFBP-3 forward, 5'-GACGACGTACATTGCCTCAG-3', and reverse, 5'-GTCTTTTGTGCAAAATAAGGCATA-3'. Real-time PCR was performed using a Light Cycler with FastStart Essential DNA Green Master (both from Roche Diagnostics) (Table III). The expression of these genes was normalized to $18 \mathrm{~S}$.

Cell lines and culture conditions. Expression of SGLT2 was confirmed by western blot for the HT29, HCT116, SW837, and SW480 human CRC cell lines, and Huh7 human hepatoma cell line. Huh7 was used as a positive control (25). These cell lines were obtained from the JCRB Cell Bank (Osaka, Japan). All cell lines were authenticated via short tandem repeat analysis by PCR and were certified to be free of bacteria, fungi and mycoplasmas by the cell bank. These cell lines were grown in appropriate media according to the instructions of cell bank. 
Cells were subjected to experiments within 6 months after receipt. All the cells were maintained in Dulbecco's modified Eagle's medium supplemented with $10 \%$ fetal bovine serum and $1 \%$ penicillin/streptomycin (all from Sigma-Aldrich; Merck $\mathrm{KGaA}$ ) in an incubator at $37^{\circ} \mathrm{C}$ under a humidified atmosphere containing $5 \% \mathrm{CO}_{2}$.

Protein extraction and western blot analysis. Total protein was extracted from the cultured cells and equivalent amounts of protein $(20 \mu \mathrm{g} /$ lane $)$ were examined by western blot as previously reported (32). The primary antibodies against SGLT2 (cat. no. 24654-1-AP) were obtained from ProteinTech Group, Inc. and glyceraldehyde-3-phosphate dehydrogenase (GAPDH; product no. 2118) was obtained from Cell Signaling Technology, Inc. GAPDH served as a loading control.

Cell proliferation assays. SW480 and HT29 cells were seeded in 96-well plates. On the following day, the cells were treated with indicated concentrations $(0,0.05,0.5,5$, and $50 \mu \mathrm{M})$ of tofogliflozin for $48 \mathrm{~h}$. The cell proliferation assays were performed by 3-(4,5-dimethylthiazol-2-yl)-5-(3-carboxymet hoxyphenyl)-2-(4-sulfophenyl)-2H-tetrazolium (MTS) assay (Promega Corporation) in accordance with the manufacturer's protocol.

Statistical analyses. The data are represented as the mean \pm standard error (SE). Differences between groups were analyzed using the Kruskal-Wallis test, then the Steel-Dwass test was performed between the groups on data to confirm statistical significance. A P-value of $<0.05$ was considered to indicate a statistically significant difference.

\section{Results}

General observations. There was no significant difference in relative kidney weight, and white adipose tissue weight among all the groups (Table I). The body weight of tofogliflozin-treated mice was relatively increased compared to the control, which is consistent with a previous study demonstrating the body weight gain in SGLT2 inhibitor-treated mice (33). During the experiment, there were no clinical symptoms in all the groups. Histopathological examination did not reveal toxicity of tofogliflozin in the livers and the kidneys (data not shown).

Serum parameters. The serum concentrations of glucose, insulin, total cholesterol, FFA, and TG in each group are listed in Table II. There were no significant differences in the results between the groups of mice treated with AOM alone and AOM followed by tofogliflozin. In this study, no adverse effect on serum parameters was observed after tofogliflozin administration in the experimental mice.

AOM-induced colorectal pre-neoplastic lesions in the experimental mice. Colorectal pre-neoplastic lesions BCAC $(34,35)$ were developed in the colons of AOM-injected mice with and without administration of tofogliflozin. Optical microscopic representative images of AOM-induced BCACs are presented in Fig. 1A. BCACs developed in the colon and rectum of all the mice injected with AOM (Groups 2 and 3), but not in the Group 1 and 4 mice that did not receive AOM. As revealed in Fig. 1B, the number of BCACs was significantly less in the mice treated with AOM plus tofogliflozin as compared to the ones treated with $\mathrm{AOM}$ alone $(72 \%$ reduction, $\mathrm{P}<0.05)$.

Effects of tofogliflozin on serum levels of TNF- $\alpha$, chronic inflammation, and insulin-like growth factor signals in colorectal mucosa of the experimental mice. TNF- $\alpha$ is an essential tumor promoter involved in obesity, inflammation, and carcinogenesis $(36,37)$. Previous studies have indicated that chronic inflammation and activation of the IGF/IGF-IR axis are involved in colorectal carcinogenesis $(16,38,39)$. Therefore, the serum levels of TNF- $\alpha$ were estimated by enzyme-linked immunosorbent assay (ELISA). The mRNA expression of the specific molecules associated with chronic inflammation and IGF signals, such as TNF- $\alpha$, F4/80, CCL2, IGF1, IGF2, and IGFBP3, in colonic mucosa, was evaluated by qRT-PCR. Serum TNF- $\alpha$ levels tended to be lower in the AOM plus tofogliflozin-treated group as compared to the AOM-treated group, however the change was not statistically significant (Fig. 2A). There were also no statistically significant differences in the expression of the analyzed genes between the AOM plus tofogliflozin-treated group and the AOM-treated group, however, IGF1 was decreased by treatment with tofogliflozin. In addition, although there were no significant differences, the expression levels of TNF- $\alpha$ and F4/80 in the colon mucosa were also decreased in the tofogliflozin-treated group compared to the no treatment group (Fig. 2B and C).

Effects of tofogliflozin on chronic inflammation and macrophage infiltration in white adipose tissue of experimental mice. Macrophages play significant roles in pro-inflammation in obese adipose tissues $(40,41)$. In the present study, immunohistochemical staining for F4/80 was performed, which revealed significant higher macrophage infiltrations in the white adipose tissues of the AOM-treated mice as compared to the mice without AOM treatment (Fig. 3A). However, the number of F4/80 positive cells were decreased 0.25 -fold in the mice treated with AOM/tofogliflozin as compared to those treated with AOM alone (Fig. 3B). In addition, it was investigated whether tofogliflozin administration attenuated chronic inflammation and decreased macrophage infiltration in the white adipose tissues. The expression of the genes associated with chronic inflammation, such as TNF- $a$ and $C C L 2$, analyzed by qRT-PCR in the white adipose tissues tended to be lower in the AOM plus tofogliflozin-treated group as compared to the AOM-treated group, although the differences were not statistically significant (Fig. 3C). These results indicated that administration of tofogliflozin attenuated the inflammatory response in the white adipose tissues of the diabetic mice.

Effects of tofogliflozin on cellular proliferation in the colorectal cancer cells. Recent studies have demonstrated that several types of cancer cells exhibit SGLT2 expression (24-26). Therefore, the expression of SGLT2 in four human CRC cell lines, HT29, HCT116, SW837, and SW480 cells were examined. As revealed in Fig. 4A, western blot analysis revealed that SGLT2 was detected in these cells as well as the hepatoma cell line Huh7 (positive control) (25). To evaluate whether tofogliflozin could directly inhibit the growth of CRC cells, a cell proliferation assay was performed using 
Table I. General observations of the experimental mice.

Relative weight ( $\mathrm{g} / 100 \mathrm{~g}$ body weight) of:

\begin{tabular}{llccccc}
\cline { 5 - 6 } Group & Treatment & No. of mice & Body weight $(\mathrm{g})$ & Liver & Kidneys & White adipose tissue \\
\hline 1 & No treatment & 5 & $40.4 \pm 4.5^{\mathrm{a}}$ & $6.4 \pm 0.3$ & $1.6 \pm 0.3$ & $5.8 \pm 0.5$ \\
2 & AOM & 9 & $40.9 \pm 2.1$ & $4.7 \pm 0.3$ & $1.1 \pm 0.1$ & $5.5 \pm 0.2$ \\
3 & AOM/tofogliflozin & 5 & $39.0 \pm 2.0$ & $5.1 \pm 0.1$ & $1.2 \pm 0.1$ & $5.1 \pm 0.2$ \\
4 & Tofogliflozin & 5 & $52.0 \pm 2.9$ & $4.4 \pm 0.2$ & $1.0 \pm 0.1$ & $5.3 \pm 0.3$ \\
\hline
\end{tabular}

${ }^{\mathrm{a} M e a n} \pm \mathrm{SE}$. AOM, azoxymethane.

Table II. Serum parameters of the experimental mice.

\begin{tabular}{llccccc}
\hline Group & \multicolumn{1}{c}{ Treatment } & Glucose $(\mathrm{mg} / \mathrm{dl})$ & Insulin $(\mathrm{ng} / \mathrm{ml})$ & Total cholesterol $(\mathrm{mg} / \mathrm{dl})$ & FFA $(\mu \mathrm{EQ} / \mathrm{l})$ & TG $(\mathrm{mg} / \mathrm{dl})$ \\
\hline 1 & No treatment & $581.0 \pm 19.0^{\mathrm{a}}$ & $4.5 \pm 1.2$ & $203.6 \pm 39.9$ & $1542.8 \pm 350.0$ & $194.4 \pm 52.5$ \\
2 & AOM & $304.9 \pm 50.8$ & $2.6 \pm 0.4$ & $155.9 \pm 33.6$ & $1614.7 \pm 187.5$ & $40.8 \pm 5.4^{\mathrm{b}}$ \\
3 & AOM/tofogliflozin & $223.4 \pm 71.8^{\mathrm{b}}$ & $2.7 \pm 0.6$ & $122.4 \pm 9.3$ & $956.8 \pm 54.5^{\mathrm{c}}$ & $28.4 \pm 7.7^{\mathrm{b}, \mathrm{c}}$ \\
4 & Tofogliflozin & $329.6 \pm 69.8$ & $3.5 \pm 0.3$ & $167.2 \pm 12.3$ & $1446.8 \pm 135.9$ & $214.4 \pm 45.8^{\mathrm{d}}$ \\
\hline
\end{tabular}

${ }^{\mathrm{a}}$ Mean \pm SE. ${ }^{\mathrm{b}}$ Significantly different from group $1(\mathrm{P}<0.05)$. ${ }^{\mathrm{c}}$ Significantly different from group $4(\mathrm{P}<0.05)$. ${ }^{\mathrm{d}}$ Significantly different from group $2(\mathrm{P}<0.05)$. AOM, azoxymethane; FFA, free fatty acid; TG, triglyceride.

Table III. Steps and conditions of thermocycling for qRT-PCR.

\begin{tabular}{lccr}
\hline Step & Target temperature & Hold time & Cycles \\
\hline Initial denaturation & $95^{\circ} \mathrm{C}$ & $10 \mathrm{~min}$ & 1 \\
Amplification-denaturation & $95^{\circ} \mathrm{C}$ & $10 \mathrm{sec}$ & 45 \\
Amplification-annealing & $60^{\circ} \mathrm{C}$ & $10 \mathrm{sec}$ & \\
Amplification-elongation & $72^{\circ} \mathrm{C}$ & $15 \mathrm{sec}$ & 1 \\
Melting-initial stage & $60^{\circ} \mathrm{C}\left(5^{\circ} \mathrm{C} / \mathrm{sec}\right)$ & $20 \mathrm{sec}$ & 1 \\
Melting-final stage & $95^{\circ} \mathrm{C}\left(0.1^{\circ} \mathrm{C} / \mathrm{sec}\right)$ & $20 \mathrm{sec}$ & 1 \\
Cooling & $40^{\circ} \mathrm{C}\left(2^{\circ} \mathrm{C} / \mathrm{sec}\right)$ & $10 \mathrm{sec}$ & \\
\hline
\end{tabular}

SGLT2-expressing HT29 and SW480 cells. The MTS assay indicated that treatment with tofogliflozin exhibited no effects on the proliferation of these cells (Fig. 4B).

\section{Discussion}

Diabetes mellitus is associated with a greater risk of CRC. According to a meta-analysis, the overall hazard ratio for CRC-specific incidence was 1.26 , and CRC-specific mortality was 1.38 in patients with diabetes as compared to those without diabetes (42). CRC and diabetes share several cellular and molecular pathways, including epithelial cell injury, activation of inflammation, and Wnt/ $\beta$-catenin pathways (43). Recently, researches on inhibition of colorectal carcinogenesis by agents for diabetes have been actively conducted. Among them, metformin was revealed to reduce the risk of CRC-specific death by $34 \%$ in the CRC patients as compared to those in the non-users (17). Intake of $\alpha$-glucosidase inhibitors is an independent factor associated with a decreased risk of colorectal neoplasia (18). In the present study, we have provided, to the best of our knowledge for the first time, the evidence to demonstrate that the anti-diabetic SGLT2 inhibitor tofogliflozin suppressed AOM-induced colorectal carcinogenesis in diabetic and obese $d b / d b$ mice. SGLT2 inhibitors are oral anti-diabetic medicines that promote urinary glucose excretion leading to a reduction of hyperglycemia (20).

Chronic inflammation is one of the key mechanisms in diabetes- and obesity-related CRC development. Notably, enhanced inflammation in the adipose tissue is known as a key feature linking obesity with the development and progression of CRC (3). Infiltration of the macrophages into white adipose tissues is considered an important phenomenon for the development of chronic systemic inflammation at an early phase, which usually coexists with the production of TNF- $\alpha$ (40). In this study, treatment with tofogliflozin reduced the expression of TNF- $\alpha$ and CCL2 in the white adipose tissues of the 

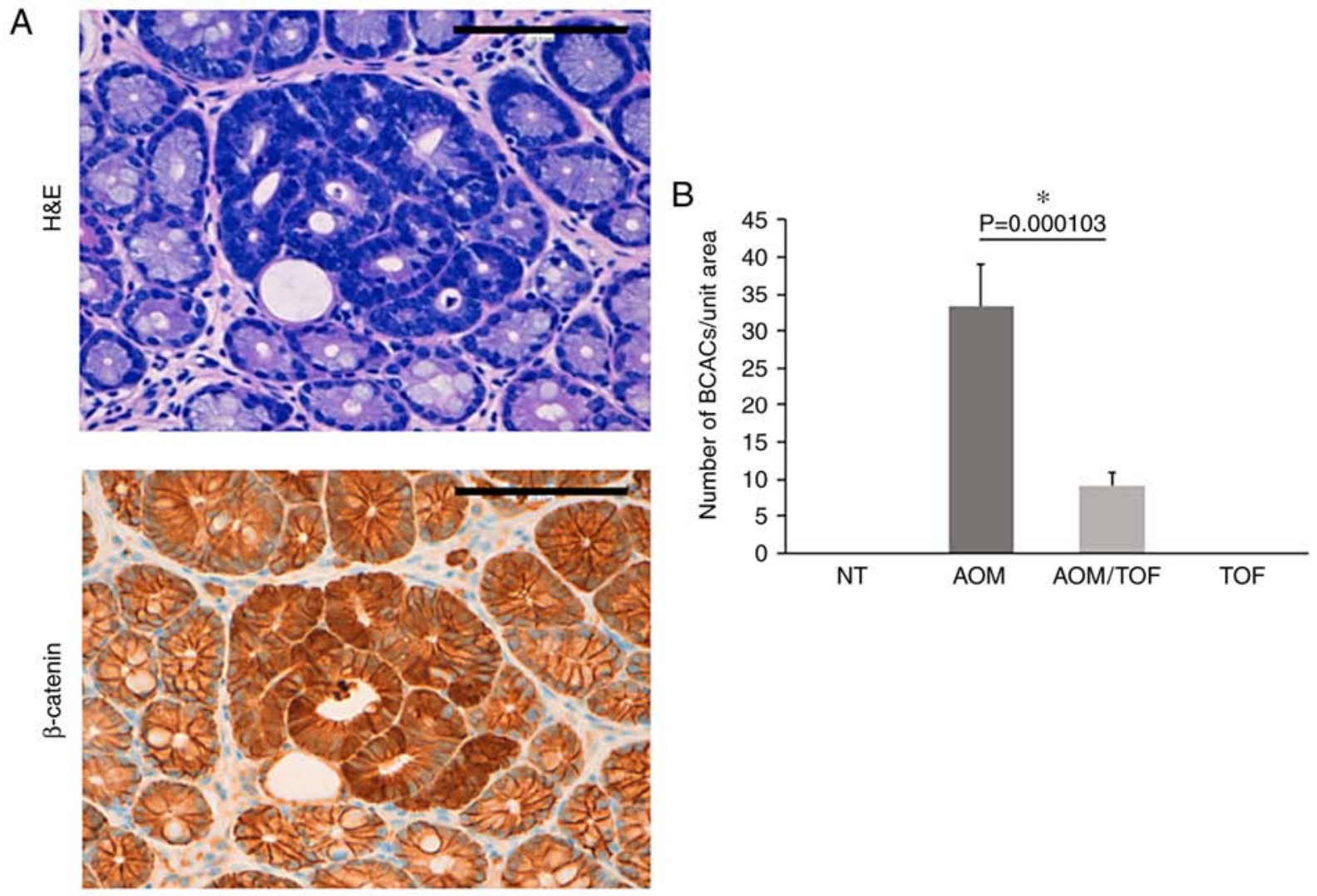

Figure 1. Development of BCAC in the colorectum of the experimental mice. (A) Representative images of BCACs (H\&E staining and immunohistochemistry for $\beta$-catenin) on the colonic mucosa of the experimental mice treated with AOM. The atypical cryptal cells in BCAC had hyperchromatic nuclei and a basophilic cytoplasm. The localization of the accumulated $\beta$-catenin protein was apparent in the cytoplasm and nucleus of colonic atypical crypts. Scale bars, $100 \mu \mathrm{m}$. (B) The number of BCACs formed in the colorectum. The values are expressed as the mean $\pm \mathrm{SE}$. "P<0.05. BCAC, $\beta$-catenin accumulated crypt; H\&E, hematoxylin and eosin; NT, no treatment; AOM, azoxymethane; TOF, tofogliflozin.
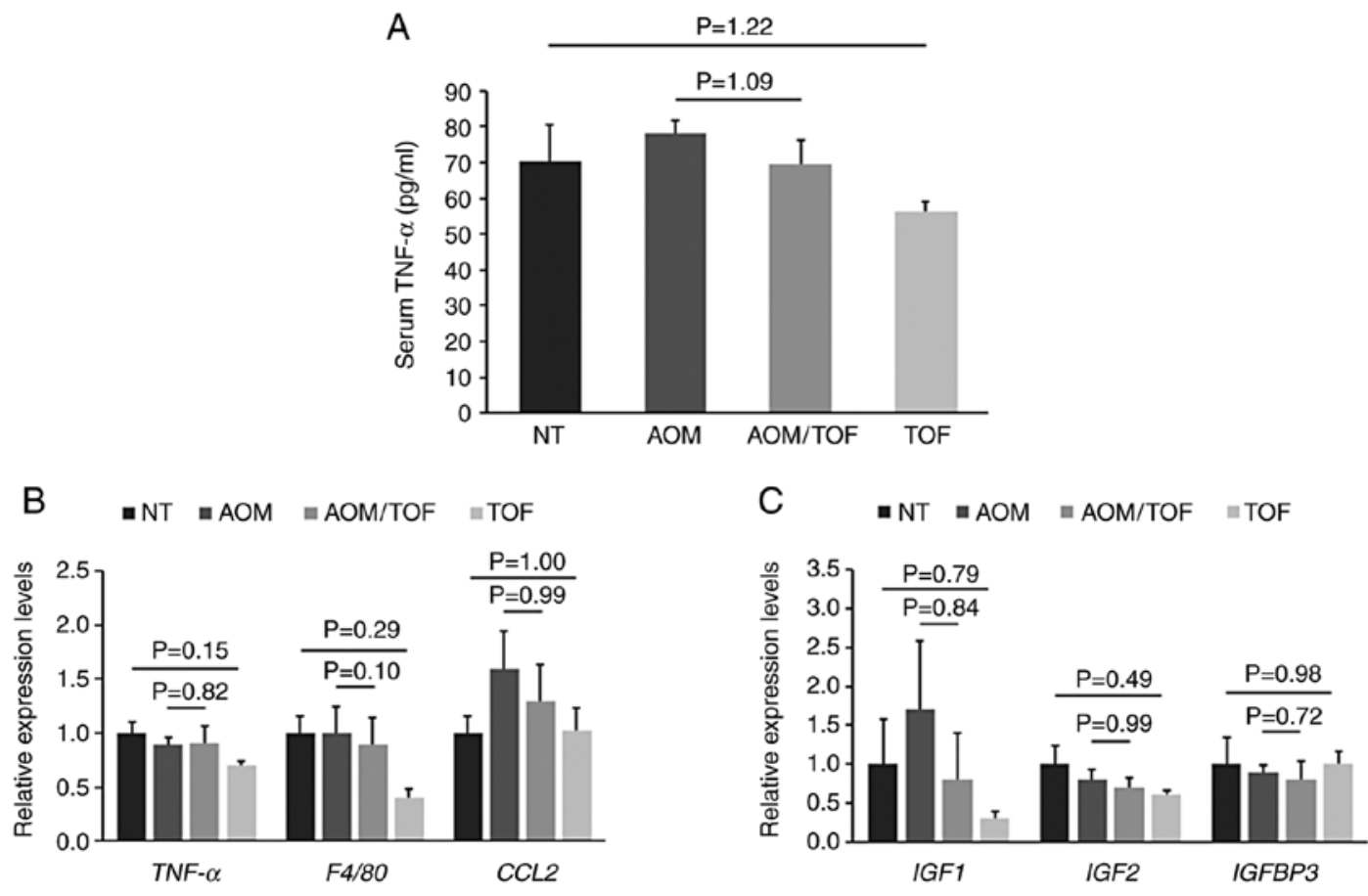

Figure 2. Effects of tofogliflozin on the serum levels of TNF- $\alpha$ and the expression levels of mRNA associated with inflammation and IGF signaling in the colonic mucosa of the experimental mice. (A) The serum concentrations of TNF- $\alpha$ were assessed by an enzyme immunoassay. Total RNA was isolated from scraped colonic mucosa of mice of all groups, and the expression levels of mRNA involved in (B) inflammation (TNF- $\alpha$, F4/80, and CCL2) and (C) IGF signaling (IGF1, IGF2, and IGFBP3) were examined by qRT-PCR with specific primers. Values are expressed as the mean \pm SE. NT, no treatment. AOM, azoxymethane. TOF, tofogliflozin. TNF- $\alpha$, tumor necrosis factor- $\alpha$; CCL-2, C-C motif chemokine-2; IGF-1, insulin-like growth factor-1; IGF-2, insulin-like growth factor-2; IGFBP-3, insulin-like growth factor binding protein-3. 
A

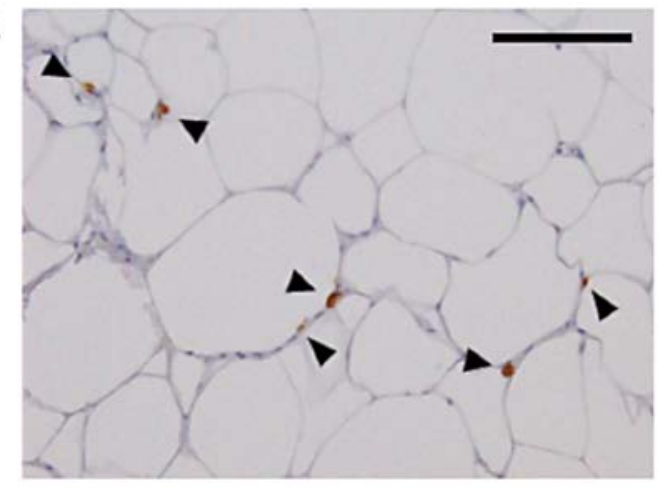

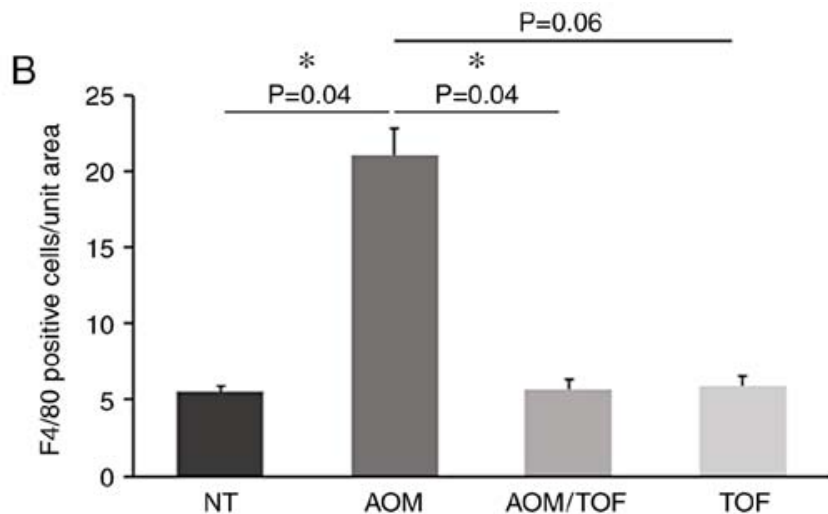

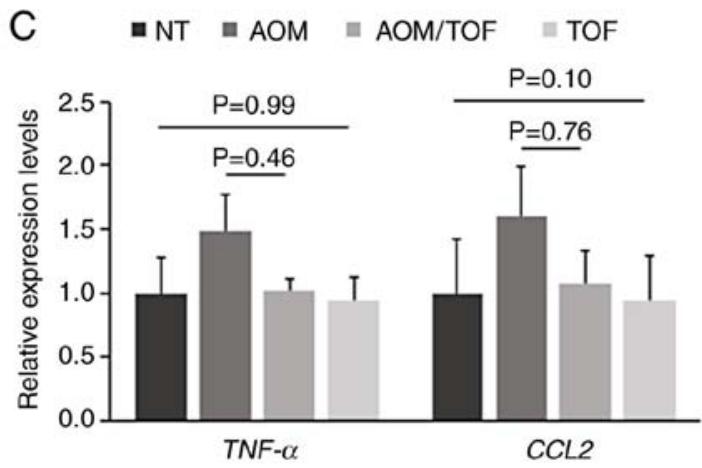

Figure 3. Effect of tofogliflozin treatment on macrophage infiltration and the expression levels of mRNA associated with inflammation in the white adipose tissue of the experimental mice. (A) Immunohistochemical staining for F4/80 in the white adipose tissue of the mice. F4/80-stained cells are observed (arrow heads). Scale bar, $100 \mu \mathrm{m}$. (B) The number of F4/80 positive cells per unit area was counted. (C) Total RNA was isolated from white adipose tissue of mice of all groups, and the expression levels of mRNA involved in inflammation (TNF- $\alpha$ and CCL2) were examined by qRT-PCR with specific primers. The values are expressed as the mean $\pm \mathrm{SE}$. ${ }^{*} \mathrm{P}<0.05$. NT, no treatment. AOM, azoxymethane. TOF, tofogliflozin; TNF- $\alpha$, tumor necrosis factor- $\alpha$; CCL-2, C-C motif chemokine-2.

A

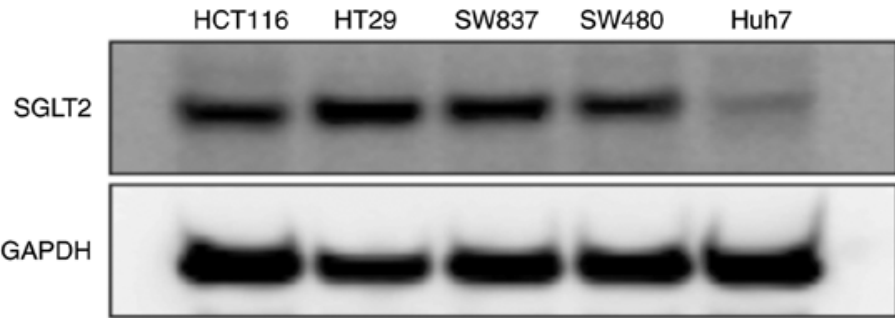

B

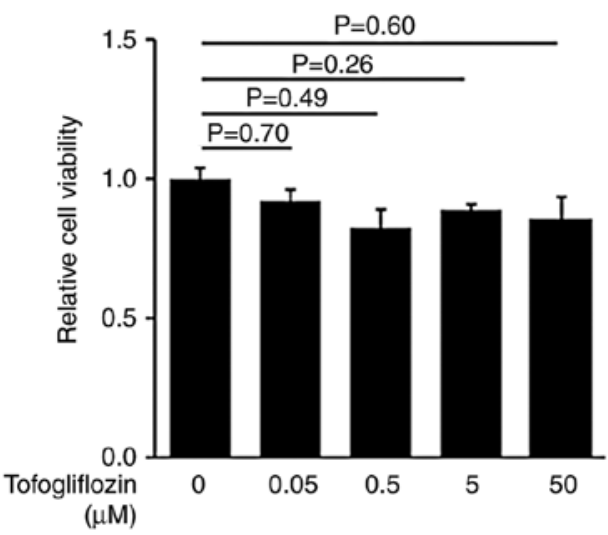

SW480

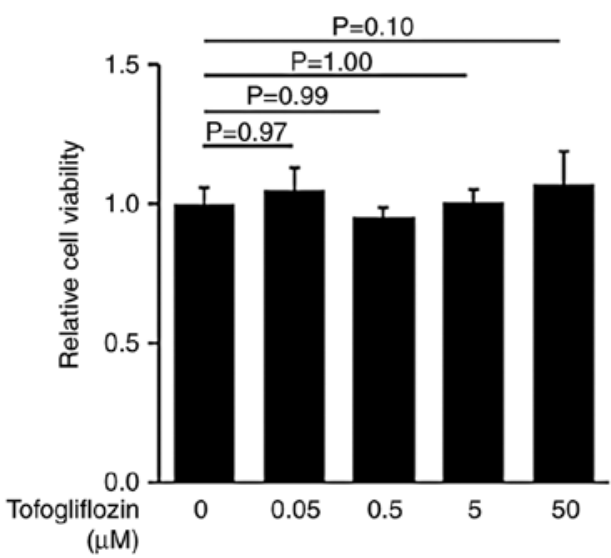

Figure 4. Protein levels of SGLT2 in human colorectal cancer cells and effects of tofogliflozin on the proliferation of the cells. (A) Total protein was extracted from colorectal cancer and hepatoma cell lines and examined by western blot analysis with equivalent amounts of protein (20 $\mu \mathrm{g} / \mathrm{lane})$. Primary antibodies for SGLT2 and GAPDH were used. GAPDH served as a loading control. The hepatoma cell line Huh7 was used as a positive control. (B) Proliferation assay of cells treated with different concentrations of tofogliflozin. Values are expressed as the mean \pm SE. SGLT2, glucose cotransporter 2; GAPDH, glyceraldehyde-3-phosphate dehydrogenase. 
AOM-administered mice. In addition, macrophage accumulation in adipose tissue, analyzed by immunohistochemistry for F4/80, was significantly inhibited by tofogliflozin. These findings indicated that attenuation of adipose tissue inflammation through inhibition of macrophage infiltration is important to prevent the development of colorectal carcinogenesis in $\mathrm{db} / \mathrm{db}$ mice. The decreasing tendency of the level of TNF- $\alpha$ in serum in the tofogliflozin-treated mice was due to the reduction of chronic inflammation in adipose tissues. Consistent with these findings, recent studies have also indicated that SGLT2 inhibitors could attenuate chronic inflammation in the adipose tissues as well as in the liver $(25,44)$, suggesting that the anti-inflammatory effects of SGLT2 inhibitors may be a novel action of these agents apart from lowering blood glucose.

The IGF/IGF-IR system is generally considered to play a significant role in colorectal carcinogenesis and is one of the molecular targets for the prevention and treatment of CRC $(16,45)$. An increased level of IGF-1 is related to a higher risk of CRC, while genetic reduction of IGF-1 could suppress colorectal carcinogenesis $(46,47)$. The results of the present study demonstrated that the expression of IGF-1 in the colonic mucosa of mice was decreased by tofogliflozin. In a similar experimental model, a type of green tea-containing catechins was revealed to suppress CRC tumorigenesis by blocking IGF signals in the colorectal mucosa (16). Collectively, these results indicated that tofogliflozin may prevent the development of diabetes- and obesity-related colorectal tumorigenesis, at least in part, through amelioration of the hyperglycemic condition and inhibition of IGF signaling.

Tofogliflozin has been reported to be a potent and highly specific SGLT2 inhibitor which improves glycemic control in diabetic rodents and human patients $(48,49)$. Consistent with previous studies, the present study demonstrated that administration of tofogliflozin lowered blood glucose levels in experimental mice, although no statistical significance was reached. Recently, it was reported by Wu et al that one of the factors contributing as a link between diabetes and cancer may be a high glucose environment (11). They indicated that a hyperglycemic state could drive genetic and epigenetic alterations, in which high glucose may lead to destabilization of the tumor suppressor ten-eleven translocation (TET)-2 through dysregulation of 5-hydroxymethylcytosine.

Originally, only proximal renal tubules were reported to contain SGLT2 (50). However, recent studies have demonstrated that cancer cells also express SGLT2 $(24,25)$ and inhibition of this glucose transporter leads to the reduction in the growth of several types of cancer, including that of the pancreas, prostate, and liver (24-26). In the present study, it was demonstrated for the first time that SGLT2 is also expressed in CRC cell lines. A cell proliferation assay revealed that tofogliflozin displayed no significant alteration of CRC cell growth, suggesting that this agent has no direct effects on CRC and possibly on colonic tumorigenesis. These findings are consistent with a previous study in which tofogliflozin was not found to exhibit suppressive effects on the growth of hepatoma cell lines (25). Other SGLT2 inhibitors, however, have been reported to show direct effects on cancer proliferation (24). The difference among several SGLT2 inhibitors may be due to SGLT2 selectivity. Most of the SGLT2 inhibitors have the inhibitory effects on SGLT1 as well as SGLT2. SGLT1 is reported to display antitumor effects, especially when co-expressed with receptor tyrosine kinase EGFR, in many types of cancers including CRC (51-55), indicating that SGLT1 may have an important efficacy on cancer proliferation. The selectivity of tofogliflozin toward SGLT2 vs. SGLT1 was revealed to be the highest among SGLT2 inhibitors under clinical development (49), suggesting that inhibition of SGLT1 by 'SGLT2' inhibitors played a role when using the inhibitors other than tofogliflozin. Further studies to investigate the roles of SGLTs and other glucose transporters in cancer cells are required.

In summary, the present study demonstrated that administration of the SGLT2 inhibitor tofogliflozin markedly suppressed colorectal carcinogenesis in AOM-injected $d b / d b$ mice, presumably through attenuation of chronic inflammation induced by obesity and diabetes. The risk of CRC is increased by diabetes and obesity and their related metabolic abnormalities. Therefore, the abnormalities, including chronic inflammation and hyperglycemic state, may be effective therapeutic targets for preventing CRC in patients having these co-existing conditions. Since SGLT2 inhibitors are used in clinical practice without causing severe adverse reactions (56), further studies should investigate whether this class of drug can be used for CRC chemoprevention in diabetic individuals.

\section{Acknowledgements}

The authors would like to thank Akihiro Abe and Toshiki Ohta for technical assistance with the experiments. The authors are also grateful to Miho Yagi, Chiyoko Sano, Hitomi Fujisawa, and Eriko Kunishima for secretarial assistance.

\section{Funding}

The present study was supported in part by Grants-in-Aid from the Ministry of Education, Science, Sports, and Culture of Japan (nos. 25860529, 16K09352, and 17K15936).

\section{Availability of data and materials}

The datasets used and analysed during the present study are available from the corresponding author on reasonable request.

\section{Authors' contributions}

JK, YS, MS and MO conceived and designed the experiments. JK, YS, MO, TM, MK, HS and TT performed the experiments. JK, YS, MO, TI and TT analyzed the data. JK, YS and MS wrote the paper. All authors read and approved the manuscript and agree to be accountable for all aspects of the research in ensuring that the accuracy or integrity of any part of the work are appropriately investigated and resolved.

\section{Ethics approval and consent to participate}

The experimental protocol was approved by the Committee of Institutional Animal Experiments of Gifu University (authorization code: 30-7, dated 13 April 2018).

\section{Patients consent for publication}

Not applicable. 


\section{Competing interests}

The authors declare that they have no competing interests.

\section{References}

1. Torre LA, Bray F, Siegel RL, Ferlay J, Lortet-Tieulent J and Jemal A: Global cancer statistics, 2012. CA Cancer J Clin 65: 87-108, 2015

2. Giovannucci E and Michaud D: The role of obesity and related metabolic disturbances in cancers of the colon, prostate, and pancreas. Gastroenterology 132: 2208-2225, 2007.

3. Gunter MJ and Leitzmann MF: Obesity and colorectal cancer: Epidemiology, mechanisms and candidate genes. J Nutr Biochem 17: 145-156, 2006.

4. Cade WT: Diabetes-related microvascular and macrovascular diseases in the physical therapy setting. Phys Ther 88: 1322-1335, 2008

5. Calle EE, Rodriguez C, Walker-Thurmond $\mathrm{K}$ and Thun MJ: Overweight, obesity, and mortality from cancer in a prospectively studied cohort of U.S. adults. N Engl J Med 348 : 1625-1638, 2003.

6. Giovannucci E, Harlan DM, Archer MC, Bergenstal RM, Gapstur SM, Habel LA, Pollak M, Regensteiner JG and Yee D: Diabetes and cancer: A consensus report. Diabetes Care 33: $1674-1685,2010$

7. Kasuga M, Ueki K, Tajima N, Noda M, Ohashi K, Noto H, Goto A, Ogawa W, Sakai R, Tsugane S, et al: Report of the Japan diabetes Society/Japanese cancer association joint committee on diabetes and cancer. Cancer Sci 104: 965-976, 2013

8. Ishino K, Mutoh M, Totsuka Y and Nakagama H: Metabolic syndrome: A novel high-risk state for colorectal cancer. Cancer Lett 334: 56-61, 2013.

9. Pais R, Silaghi H, Silaghi AC, Rusu ML and Dumitrascu DL: Metabolic syndrome and risk of subsequent colorectal cancer World J Gastroenterol 15: 5141-5148, 2009.

10. Shimizu M, Kubota M, Tanaka T and Moriwaki H: Nutraceutical approach for preventing obesity-related colorectal and liver carcinogenesis. Int J Mol Sci 13: 579-595, 2012.

11. Wu D, Hu D, Chen H, Shi G, Fetahu IS, Wu F, Rabidou K, Fang R, Tan L, Xu S, et al: Glucose-regulated phosphorylation of TET2 by AMPK reveals a pathway linking diabetes to cancer. Nature 559: 637-641, 2018.

12. Hata K, Kubota M, Shimizu M, Moriwaki H, Kuno T, Tanaka T, Hara A and Hirose Y: Monosodium glutamate-induced diabetic mice are susceptible to azoxymethane-induced colon tumorigenesis. Carcinogenesis 33: 702-707, 2012.

13. Tuominen I, Al-Rabadi L, Stavrakis D, Karagiannides I, Pothoulakis C and Bugni JM: Diet-induced obesity promotes colon tumor development in azoxymethane-treated mice. PLoS One 8: e60939, 2013.

14. Fukuta K, Shirakami Y, Maruta A, Obara K, Iritani S Nakamura N, Kochi T, Kubota M, Sakai H, Tanaka T and Shimizu M: Preventive effects of pentoxifylline on the development of colonic premalignant lesions in obese and diabetic mice. Int J Mol Sci 18: pii: E413, 2017.

15. Kubota M, Shimizu M, Sakai H, Yasuda Y, Terakura D, Baba A, Ohno T, Tsurumi H, Tanaka T and Moriwaki H: Preventive effects of curcumin on the development of azoxymethane-induced colonic preneoplastic lesions in male C57BL/KsJ-db/db obese mice. Nutr Cancer 64: 72-79, 2012.

16. Shimizu M, Shirakami Y, Sakai H, Adachi S, Hata K, Hirose Y, Tsurumi H, Tanaka T and Moriwaki H: (-)-Epigallocatechin gallate suppresses azoxymethane-induced colonic premalignant lesions in male C57BL/KsJ-db/db mice. Cancer Prev Res (Phila) 1: 298-304, 2008.

17. Chang YT, Tsai HL, Kung YT, Yeh YS, Huang CW, Ma CJ, Chiu HC and Wang JY: Dose-dependent relationship between metformin and colorectal cancer occurrence among patients with type 2 Diabetes-A nationwide cohort study. Transl Oncol 11: $535-541,2018$

18. Horibe Y, Adachi S, Ohno T, Goto N, Okuno M, Iwama M, Yamauchi O,Kojima T, Saito K, Ibuka T, et al: Alpha-glucosidase inhibitor use is associated with decreased colorectal neoplasia risk in patients with type 2 diabetes mellitus receiving colonoscopy: A retrospective study. Oncotarget 8: 97862-97870, 2017.
19. Imamura M, Nakanishi K, Suzuki T, Ikegai K, Shiraki R, Ogiyama T, Murakami T, Kurosaki E, Noda A, Kobayashi Y, et al: Discovery of ipragliflozin (ASP1941): A novel C-glucoside with benzothiophene structure as a potent and selective sodium glucose co-transporter 2 (SGLT2) inhibitor for the treatment of type 2 diabetes mellitus. Bioorg Med Chem 20: 3263-3279, 2012.

20. Tahrani AA, Barnett AH and Bailey CJ: SGLT inhibitors in management of diabetes. Lancet Diabetes Endocrinol 1: 140-151, 2013.

21. Fonseca VA, Ferrannini E, Wilding JP, Wilpshaar W, Dhanjal P, Ball G and Klasen S: Active- and placebo-controlled dose-finding study to assess the efficacy, safety, and tolerability of multiple doses of ipragliflozin in patients with type 2 diabetes mellitus. J Diabetes Complications 27: 268-273, 2013.

22. Tahara A, Kurosaki E, Yokono M, Yamajuku D, Kihara R, Hayashizaki Y, Takasu T, Imamura M, Li Q, Tomiyama H, et al: Effects of sodium-glucose cotransporter 2 selective inhibitor ipragliflozin on hyperglycaemia, oxidative stress, inflammation and liver injury in streptozotocin-induced type 1 diabetic rats. J Pharm Pharmacol 66: 975-987, 2014

23. Tahara A, Kurosaki E, Yokono M, Yamajuku D, Kihara R, Hayashizaki Y, Takasu T, Imamura M, Qun L, Tomiyama H, et al: Pharmacological profile of ipragliflozin (ASP1941), a novel selective SGLT2 inhibitor, in vitro and in vivo. Naunyn Schmiedebergs Arch Pharmacol 385: 423-436, 2012.

24. Kaji K, Nishimura N, Seki K, Sato S, Saikawa S, Nakanishi K, Furukawa M, Kawaratani H, Kitade M, Moriya K, et al: Sodium glucose cotransporter 2 inhibitor canagliflozin attenuates liver cancer cell growth and angiogenic activity by inhibiting glucose uptake. Int J Cancer 142: 1712-1722, 2018

25. Obara K, Shirakami Y, Maruta A, Ideta T, Miyazaki T, Kochi T, Sakai H, Tanaka T, Seishima M and Shimizu M: Preventive effects of the sodium glucose cotransporter 2 inhibitor tofogliflozin on diethylnitrosamine-induced liver tumorigenesis in obese and diabetic mice. Oncotarget 8: 58353-58363, 2017.

26. Scafoglio C, Hirayama BA, Kepe V, Liu J, Ghezzi C, Satyamurthy N, Moatamed NA, Huang J, Koepsell H, Barrio JR and Wright EM: Functional expression of sodium-glucose transporters in cancer. Proc Natl Acad Sci USA 112: E4111-E4119, 2015.

27. Utsunomiya K, Shimmoto N, Senda M, Kurihara Y, Gunji R, Kameda H, Tamura M, Mihara $\mathrm{H}$ and Kaku K: Japanese study of tofogliflozin with type 2 diabetes mellitus patients in an observational study of the elderly (J-STEP/EL): A 12-week interim analysis. J Diabetes Investig 7: 755-763, 2016.

28. Terakura D, Shimizu M, Iwasa J, Baba A, Kochi T, Ohno T, Kubota M, Shirakami Y, Shiraki M, Takai K, et al: Preventive effects of branched-chain amino acid supplementation on the spontaneous development of hepatic preneoplastic lesions in $\mathrm{C} 57 \mathrm{BL} / \mathrm{KsJ}-\mathrm{db} / \mathrm{db}$ obese mice. Carcinogenesis 33: 2499-2506, 2012.

29. Hata K, Tanaka T, Kohno H, Suzuki R, Qiang SH, Yamada Y, Oyama T, Kuno T, Hirose Y, Hara A and Mori H: Beta-catenin-accumulated crypts in the colonic mucosa of juvenile ApcMin/+ mice. Cancer Lett 239: 123-128, 2006

30. Miyazaki T, Shirakami Y, Kubota M, Ideta T, Kochi T, Sakai H, Tanaka T, Moriwaki H and Shimizu M: Sodium alginate prevents progression of non-alcoholic steatohepatitis and liver carcinogenesis in obese and diabetic mice. Oncotarget 7: 10448-10458, 2016.

31. Shirakami Y, Shimizu M, Kubota M, Ohno T, Kochi T, Nakamura N, Sumi T, Tanaka T, Moriwaki H and Seishima M: Pentoxifylline prevents nonalcoholic steatohepatitis-related liver pre-neoplasms by inhibiting hepatic inflammation and lipogenesis. Eur J Cancer Prev 25: 206-215, 2016.

32. Shirakami Y, Gottesman ME and Blaner WS: Diethylnitrosamine-induced hepatocarcinogenesis is suppressed in lecithin:retinol acyltransferase-deficient mice primarily through retinoid actions immediately after carcinogen administration. Carcinogenesis 33: 268-274, 2012.

33. Nagata T, Fukuzawa T, Takeda M, Fukazawa M, Mori T, Nihei T, Honda K, Suzuki Y and Kawabe Y: Tofogliflozin, a novel sodium-glucose co-transporter 2 inhibitor, improves renal and pancreatic function in $\mathrm{db} / \mathrm{db}$ mice. Br J Pharmacol 170: 519-531, 2013.

34. Bird RP and Good CK: The significance of aberrant crypt foci in understanding the pathogenesis of colon cancer. Toxicol Lett 112-113: 395-402, 2000.

35. Yamada Y and Mori H: Pre-cancerous lesions for colorectal cancers in rodents: A new concept. Carcinogenesis 24: 1015-1019, 2003. 
36. Kubota M, Shimizu M, Sakai H, Yasuda Y, Ohno T, Kochi T, Tsurumi H, Tanaka T and Moriwaki H: Renin-angiotensin system inhibitors suppress azoxymethane-induced colonic preneoplastic lesions in C57BL/KsJ-db/db obese mice. Biochem Biophys Res Commun 410: 108-113, 2011.

37. Szlosarek P, Charles KA and Balkwill FR: Tumour necrosis factor-alpha as a tumour promoter. Eur J Cancer 42: 745-750, 2006.

38. Chen J, Wu A, Sun H, Drakas R, Garofalo C, Cascio S, Surmacz E and Baserga R: Functional significance of type 1 insulin-like growth factor-mediated nuclear translocation of the insulin receptor substrate-1 and beta-catenin. J Biol Chem 280: 29912-29920, 2005.

39. Itzkowitz SH and Yio X: Inflammation and cancer IV. Colorectal cancer in inflammatory bowel disease: The role of inflammation. Am J Physiol Gastrointest Liver Physiol 287: G7-G17, 2004.

40. Weisberg SP, McCann D, Desai M, Rosenbaum M, Leibel RL and Ferrante AW Jr: Obesity is associated with macrophage accumulation in adipose tissue. J Clin Invest 112: 1796-1808, 2003.

41. Xu H, Barnes GT, Yang Q, Tan G, Yang D, Chou CJ, Sole J, Nichols A, Ross JS, Tartaglia LA and Chen H: Chronic inflammation in fat plays a crucial role in the development of obesity-related insulin resistance. J Clin Invest 112: 1821-1830, 2003.

42. De Bruijn KM, Arends LR, Hansen BE, Leeflang S, Ruiter R and van Eijck $\mathrm{CH}$ : Systematic review and meta-analysis of the association between diabetes mellitus and incidence and mortality in breast and colorectal cancer. Br J Surg 100: 1421-1429, 2013.

43. Gonzalez N, Prieto I, Del Puerto-Nevado L, Portal-Nuñez S, Ardura JA, Corton M, Fernández-Fernández B, Aguilera O, Gomez-Guerrero C, Mas S, et al: 2017 update on the relationship between diabetes and colorectal cancer: Epidemiology, potential molecular mechanisms and therapeutic implications. Oncotarget 8: 18456-18485, 2017.

44. Xu L, Nagata N, Nagashimada M, Zhuge F, Ni Y, Chen G, Mayoux E, Kaneko S and Ota T: SGLT2 inhibition by empagliflozin promotes fat utilization and browning and attenuates inflammation and insulin resistance by polarizing M2 macrophages in Diet-induced obese mice. EBioMedicine 20: 137-149, 2017.

45. Ealey KN, Xuan W, Lu S and Archer MC: Colon carcinogenesis in liver-specific IGF-I-deficient (LID) mice. Int J Cancer 122: 472-476, 2008.

46. Giovannucci E, Pollak MN, Platz EA, Willett WC, Stampfer MJ, Majeed N, Colditz GA, Speizer FE and Hankinson SE: A prospective study of plasma insulin-like growth factor-1 and binding protein-3 and risk of colorectal neoplasia in women. Cancer Epidemiol Biomarkers Prev 9: 345-349, 2000.
47. Olivo-Marston SE, Hursting SD, Lavigne J, Perkins SN, Maarouf RS, Yakar S and Harris CC: Genetic reduction of circulating insulin-like growth factor-1 inhibits azoxymethane-induced colon tumorigenesis in mice. Mol Carcinog 48: 1071-1076, 2009.

48. Kaku K, Watada H, Iwamoto Y, Utsunomiya K, Terauchi Y, Tobe K, Tanizawa Y, Araki E, Ueda M, Suganami H, et al: Efficacy and safety of monotherapy with the novel sodium/glucose cotransporter-2 inhibitor tofogliflozin in Japanese patients with type 2 diabetes mellitus: A combined Phase 2 and 3 randomized, placebo-controlled, double-blind, parallel-group comparative study. Cardiovasc Diabetol 13: 65, 2014.

49. Suzuki M, Honda K, Fukazawa M, Ozawa K, Hagita H, Kawai T, Takeda M, Yata T, Kawai M, Fukuzawa T, et al: Tofogliflozin, a potent and highly specific sodium/glucose cotransporter 2 inhibitor, improves glycemic control in diabetic rats and mice. J Pharmacol Exp Ther 341: 692-701, 2012.

50. Chao EC and Henry RR: SGLT2 inhibition-a novel strategy for diabetes treatment. Nat Rev Drug Discov 9: 551-559, 2010.

51. Hanabata Y, Nakajima Y, Morita K, Kayamori K and Omura K: Coexpression of SGLT1 and EGFR is associated with tumor differentiation in oral squamous cell carcinoma. Odontology 100: 156-163, 2012.

52. Lai B, Xiao Y, Pu H, Cao Q, Jing H and Liu X: Overexpression of SGLT1 is correlated with tumor development and poor prognosis of ovarian carcinoma. Arch Gynecol Obstet 285: 1455-1461, 2012.

53. Liu H, Ertay A, Peng P, Li J, Liu D, Xiong H, Zou Y, Qiu H, Hancock D, Yuan X, et al: SGLT1 is required for the survival of triple-negative breast cancer cells via potentiation of EGFR activity. Mol Oncol 13: 1874-1886, 2019.

54. Madunić IV, Madunić J, Breljak D, Karaica D and Sabolić I: Sodium-glucose cotransporters: New targets of cancer therapy? Arh Hig Rada Toksikol 69: 278-285, 2018.

55. Ren J, Bollu LR, Su F, Gao G, Xu L, Huang WC, Hung MC and Weihua Z: EGFR-SGLT1 interaction does not respond to EGFR modulators, but inhibition of SGLT1 sensitizes prostate cancer cells to EGFR tyrosine kinase inhibitors. Prostate 73: 1453-1461, 2013.

56. Rosenwasser RF, Rosenwasser JN, Sutton D, Choksi R and Epstein B: Tofogliflozin: A highly selective SGLT2 inhibitor for the treatment of type 2 diabetes. Drugs Today (Barc) 50: 739-745, 2014. 